\title{
ARTIGO
}

\section{A relação entre ciclo menstrual e gengivite}

\author{
The relationship between the menstrual cycle and gingivitis
}

\begin{abstract}
RESUMO
A gengivite é uma doença inflamatória que interfere nos tecidos de suporte dos dentes. Inicia-se pelo acúmulo da placa bacteriana sobre as faces dentárias e a margem gengival, promovendo a liberação de produtos tóxicos que são efeitos da combinação da bactéria e do hospedeiro. Há indícios de que os hormônios sexuais, principalmente os esteroidais, que estão presentes no ciclo menstrual, apresentem efeitos sobre a saúde periodontal, causando impactos diretos na inflamação gengival e em possíveis alterações de substâncias no fluido gengival. Para tanto, realizou-se uma pesquisa de campo com o intuito de validar a relação entre o ciclo menstrual e a gengivite e seus possíveis diagnósticos frente aos hormônios sexuais que se apresentam de forma tão relevante. OBJETIVO: O objetivo do presente trabalho é verificar através de uma pesquisa de campo, se durante o ciclo menstrual, as alterações hormonais causadas neste período têm capacidade de gerar alterações nos tecidos gengivais. METODOLOGIA: Trata-se de uma pesquisa de campo, realizada por meio de artigos indexados na base científica SciELO e avaliação clínica e sondagem da gengiva de 20 voluntárias durante o período pré-mentrual, menstrual e período pós-mentrual de cada uma.
\end{abstract}

Palavras-chave: Gengivite, ciclo menstrual, hormônios.

\section{ABSTRACT}

Gingivitis is an inflammatory disease that affects the supporting tissues of the teeth. It begins by the accumulation of bacterial plaque on the dental faces and the gingival margin, promoting the release of toxic products that are effects of the combination of bacteria and the host. There are indications that the sex hormones, especially the steroidal ones, that are present in the menstrual cycle, have effects on the periodontal health, causing direct impacts on gingival inflammation and possible alterations of substances in the gingival fluid. Therefore, a field research was carried out with the purpose of validating the relationship between the menstrual cycle and gingivitis and its possible diagnoses against the sex hormones that present themselves in such a relevant way. OBJECTIVE: The objective of the present study is to verify through a field survey whether, during the menstrual cycle, the hormonal changes caused in this period have the capacity to generate alterations in the gingival tissues. METHODOLOGY: This is a field study, carried out by means of articles indexed in SciELO scientific basis and clinical evaluation and gingival probing of 20 volunteers during the pre-mentual period, menstrual period and post-mentual period of each.

\section{INTROD UÇÃO}

A doença periodontal é uma doença inflamatória que interfere nos tecidos de suporte dos dentes. Inicia-se pelo acúmulo da placa bacteriana sobre as faces dentárias e a margem gengival, promovendo a liberação de produtos tóxicos que são efeitos da combinação da bactéria e do hospedeiro. ${ }^{1}$

\section{Luiza Nunes Siqueira \\ Juliana Mara da Silva Leardini \\ Jeferson Caique de Almeida \\ Tatiany Gabrielle Freire Araújo}

Luiza Nunes Siqueira /INAPÓS/Odontologia/Rua João Basílio, 219, Pouso Alegre, MG/ luizasiqueira10@yahoo.com.br

Submetido em: 31-8-2017

Aceito em: 11-12-2018 
Devido a entrada de células bacterianas na corrente sanguínea, o sistema imunológico promove a produção de citocinas, prostaglandinas e interleucinas como meio de propagação sistêmica de anticorpos. ${ }^{1}$

Sabe-se que as doenças periodontais são provocadas por uma agressão aos tecidos mediante a proliferação bacteriana, porém, essa doença pode estar intimamente relacionada a etiologias secundárias sistêmicas que atuam alterando a resistência do tecido frente a agressão. ${ }^{2}$

No período do ciclo menstrual da mulher, vários hormônios como o folículo-estimulante (FSH), estrógeno, progesterona e luteinizante ( $\mathrm{LH}$ ) e principalmente os hormônios sexuais esteroidais são secretados alternadamente e são capazes de promover além da homeostase, alterações nas fases de pré-ovulação, ovulação, pré-menstruação e menstruação. ${ }^{2}$

Estes hormônios são responsáveis pelo controle do ciclo menstrual, uma vez que delimitam desde o processo de ovulação até o da menopausa. As variadas fases do ciclo da menstruação estão correlacionadas com a quantidade do fluido gengival e os principais períodos que influenciam diretamente na gengiva são os de ovulação e de pré-menstruação. ${ }^{3}$

\section{DESENVOLVIMENTO}

Para este estudo foram selecionadas 20 voluntarias. A pesquisa foi realizada através da aplicação de um questionário e as mesmas foram avaliadas clinicamente, seguindo alguns critérios previamente estabelecidos. O intuito da pesquisa é comprovar que, embora os hormônios sexuais não sejam capazes por si só de desenvolver quadros como a gengivite, eles exercem um impacto significativo na inflamação, visto que são capazes de alterar as respostas que o periodonto desencadeia frente ao contato com bactérias, contribuindo para a manifestação da doença.

\section{MATERIAIS E MÉTODOS}

Participaram da pesquisa 20 voluntarias que foram selecionadas aleatoriamente, descartando aquelas mulheres que estavam no período de pré menopausa ou menopausa, e as que não tinham o ciclo menstrual regulado. As voluntárias que concordaram em participar, foram submetidas a ler e assinar um termo de consentimento livre e esclarecido, de acordo com aprovação do comitê de ética em pesquisa.

A pesquisa foi realizada através da avalição clínica e sondagem do periodonto gengival das voluntarias em 3 tempos, (antes do período menstrual, durante o período menstrual e logo após o último dia de sangramento menstrual da voluntária).

As voluntarias foram submetidas também à aplicação de um questionário realizado pela pesquisadora responsável, que recolheu informações pessoais e respostas sobre os questionamentos, em relação ao ciclo menstrual e a saúde bucal.

\section{DISCUSS ÃO}

Sabe-se que a inflamação gengival, além de estar associada aos inadequados procedimentos de higiene oral, o que contribui para o acúmulo de biofilme bacteriano, também 
se encontra relacionada com as condições sistêmicas do paciente, envolvendo alterações hormonais. ${ }^{4}$

As bactérias capazes de desenvolver uma doença periodontal são gram-negativas aeróbias como a Actinobacillus, Bacteróides e Porphyromonas Gingivalis, ${ }^{5}$ e podem se localizar tanto subgengival quanto supragengival. ${ }^{6}$

Além das bactérias citadas acimas que estão presente em casos de periodontite clássica, existe a presença do microrganismo Prevotella intermedia, cujo mesmo encontra-se intimamente associado com a influência da condição hormonal da mulher durante seu período de ovulação. ${ }^{7}$

Tal microrganismo consegue se manter estável no periodonto devido ao fato de que utiliza os hormônios estrógeno e progesterona - os quais se enfatizam no período pré-menstrual e menstrual da mulher - como forma de nutrientes para sobreviverem no meio. ${ }^{7}$

Cabe ressaltar que a ação dos hormônios não só favorece o crescimento e o desenvolvimento de bactérias específicas ao periodonto, como também é capaz de alterar o metabolismo tecidual perante uma resposta imunológica ou inflamatória. ${ }^{7}$

Para tanto, deve-se salientar a suma importância de um trabalho em conjunto entre médicos e dentistas, uma vez que os médicos devem ficar atentos sobre o quanto a alteração hormonal da mulher está influenciando no periodonto e o mesmo cabe ao dentista, que deve saber identificar a causa da gengivite, juntamente aos seus aspectos clínicos, que possa ser desencadeada por alguma alteração hormonal. ${ }^{8}$

Nesta pesquisa, os exames clínicos de sondagem periodontal comprovaram que, durante o período menstrual os hormônios influenciam na gengivite, uma vez que o resultado aprovou que $55 \%$ das voluntárias submetidas ao exame, demonstraram sangramento gengival durante o período menstrual e 60\% sentiram sensibilidade maior durante esse período.

Comprovou-se também que, durante o período pré-menstrual, os hormônios estão presentes em menor quantidade, visto que somente $30 \%$ das voluntárias tiveram sangramento à sondagem.

Já no período de pós-menstruação, os hormônios estão presentes em pouquíssimas mulheres, $15 \%$ das voluntárias da pesquisa, isso se dá pelo fato de que após a menstruação, os picos hormonais abaixam e encontram-se ineficientes para causar alterações no periodonto, salvo em alguns casos devido ao metabolismo de cada indivíduo.

\section{EXAME CLÍNICO E FOTOGRÁFICO}

Para o exame clinico foram utilizadas espátulas de madeira e sonda periodontal milimetrada.

O exame foi realizado em ambiente iluminado, com os devidos meios de biossegurança.

As fotografias foram feitas para facilitar na avaliação das características clinicas do periodonto das voluntarias, utilizando-se abridores e afastadores labiais que promoveram a visualização da gengiva marginal das voluntarias.

Após a coleta dos dados, os resultados foram avaliados quantitativamente em porcentagem simples e submetidos ao teste estatístico qui-quadrado. E qualitativamente pela análise da saúde periodontal realizada através do exame clinico. 

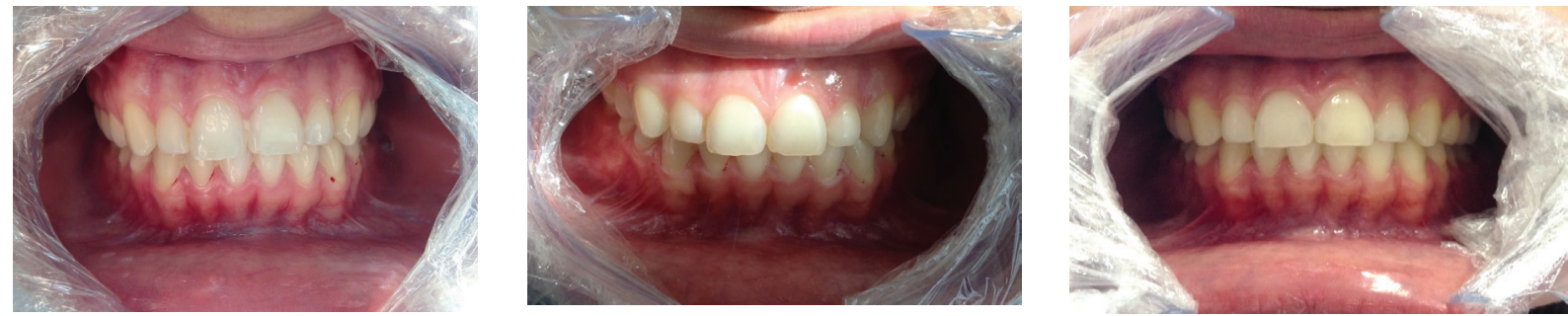

Figuras 1, 2 e 3: Imagens da voluntária 1, que apresentou sangramento nos períodos pré-menstrual e menstrual.
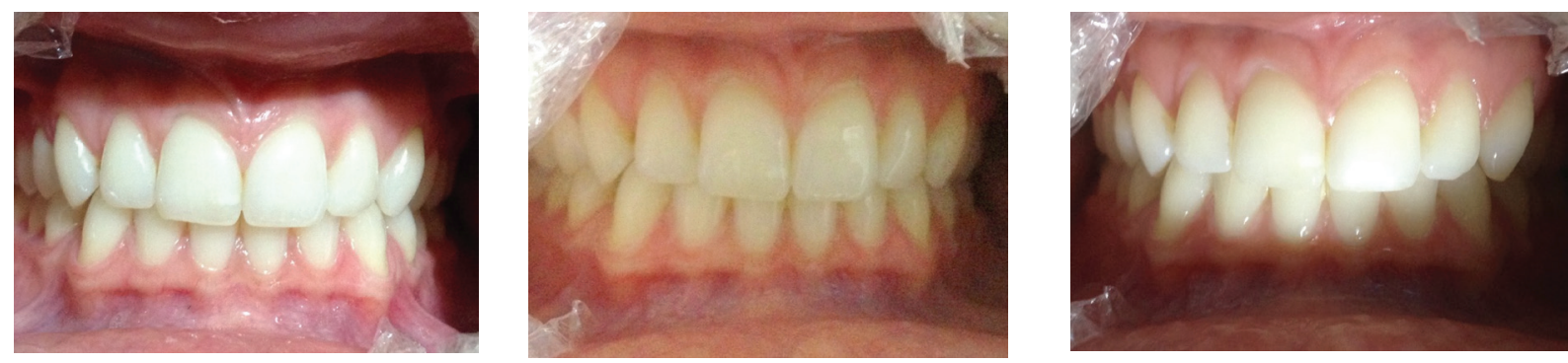

Figuras 4, 5 e 6: Imagens da voluntária 2, que não apresentou significativos sangramentos em nenhum dos períodos.
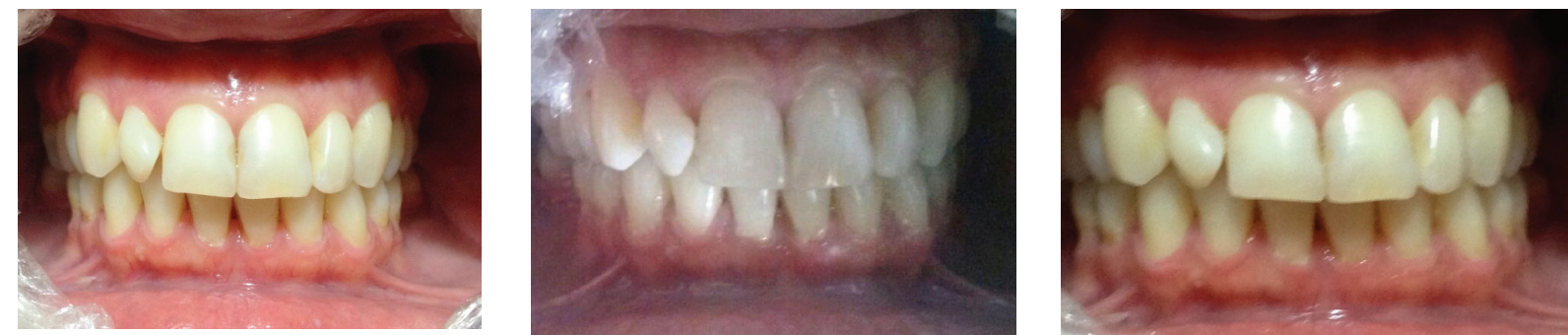

Figuras 7, 8 e 9: Imagens da voluntária 3, que não apresentou significativos sangramentos em nenhum dos períodos.
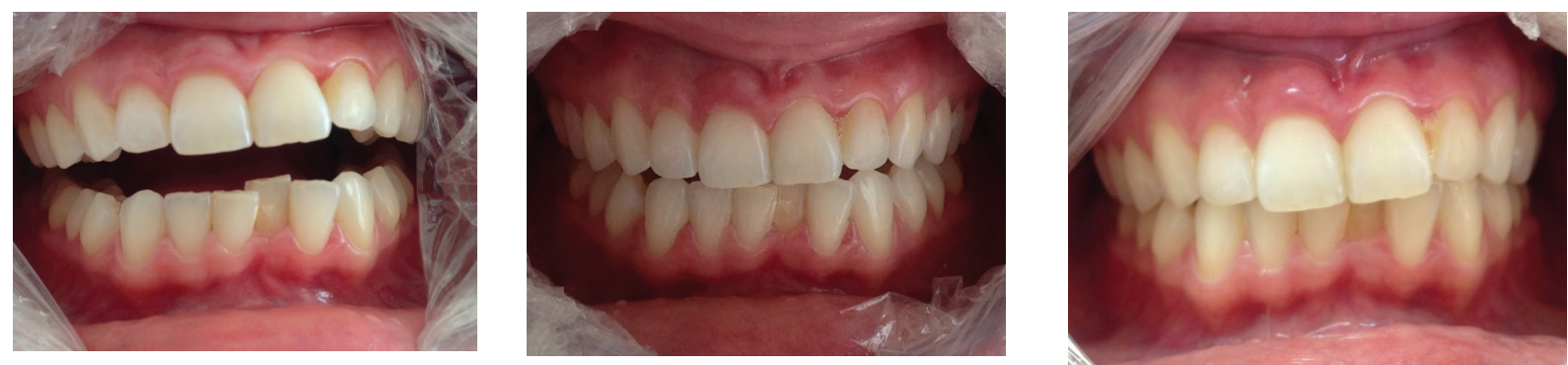

Figuras 10, 11 e 12: Imagens da voluntária 4, que apresentou sangramento no período pré-menstrual.
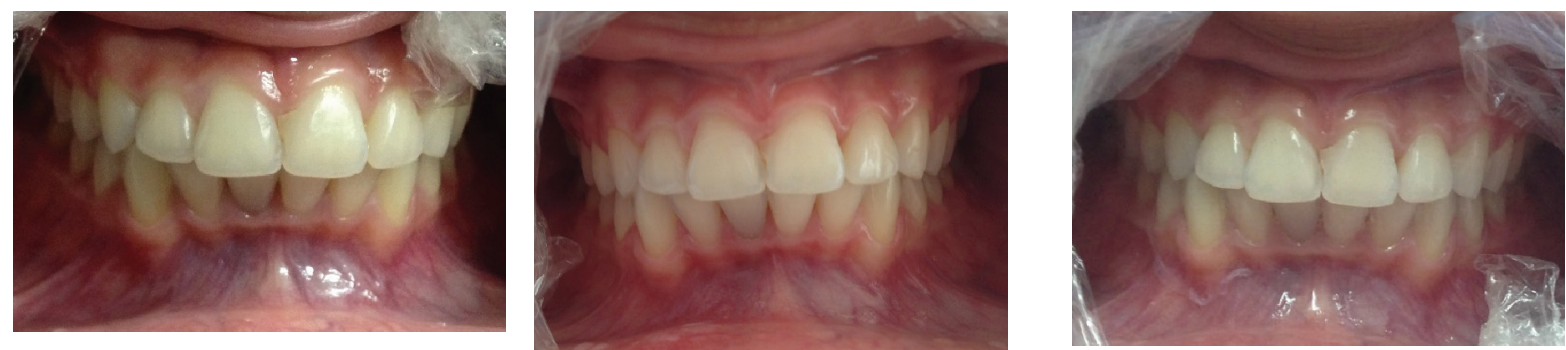

Figuras 13, 14 e 15: Imagens da voluntária 5, que não apresentou significativos sangramentos em nenhum dos períodos. 

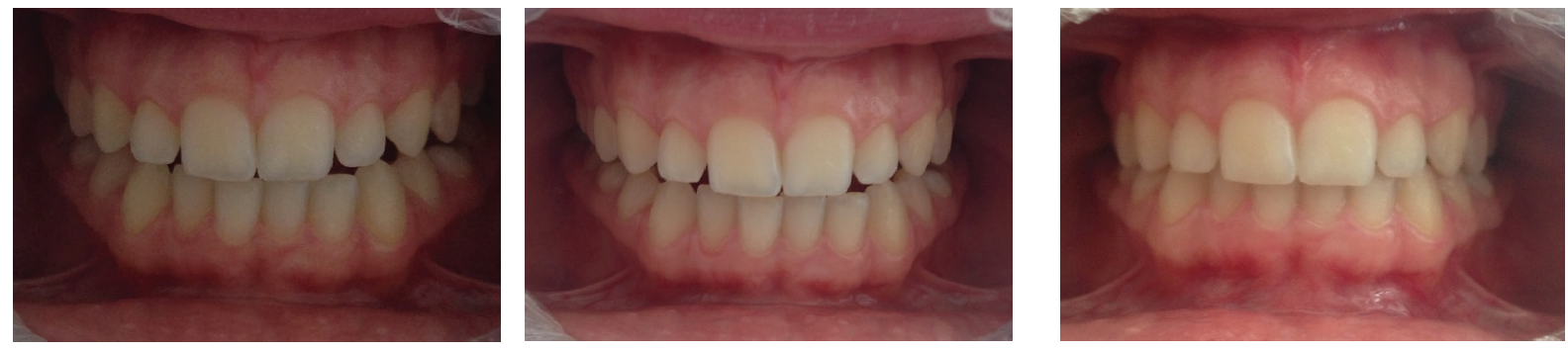

Figuras 16, 17 e 18: Imagens da voluntária 6, que não apresentou significativos sangramentos em nenhum dos períodos.
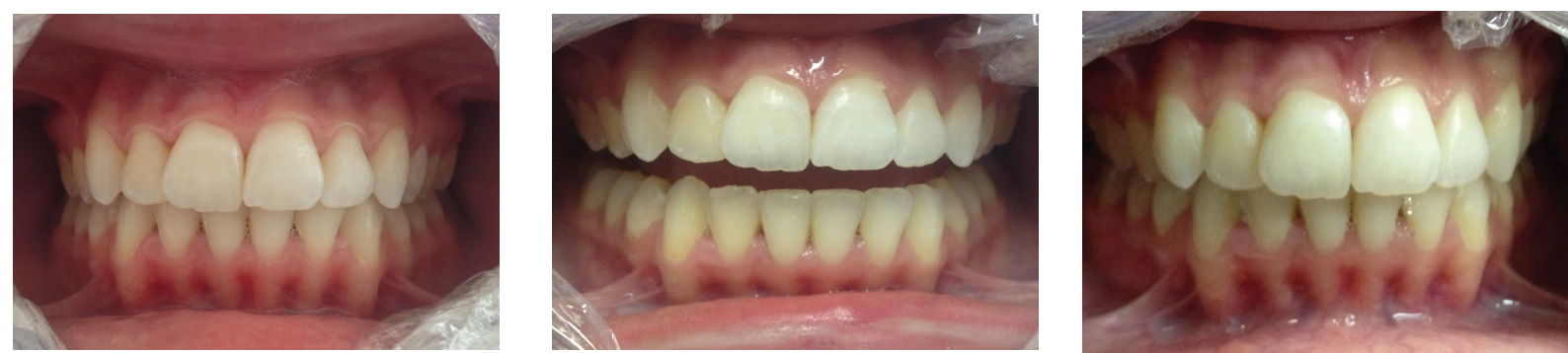

Figuras 19, 20 e 21: Imagens da voluntária 7, que não apresentou significativos sangramentos em nenhum dos períodos.
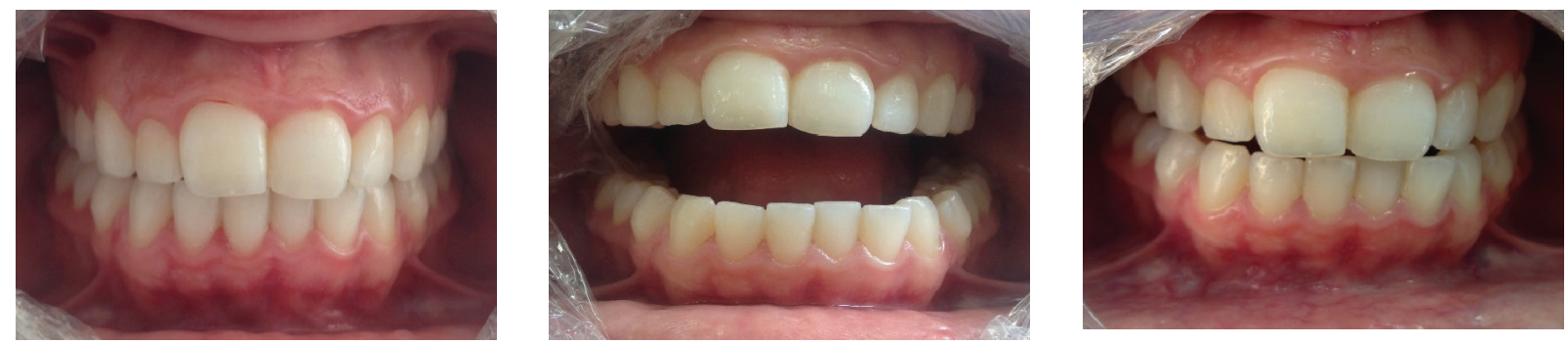

Figuras 22, 23 e 24: Imagens da voluntária 8, que apresentou sangramento no período pré-menstrual.
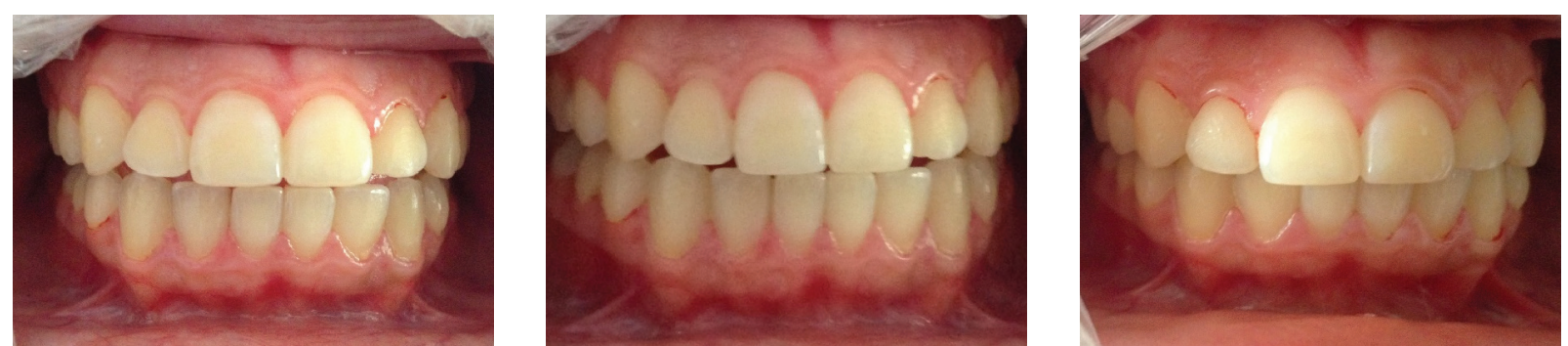

Figuras 25, 26 e 27: Imagens da voluntária 9, que apresentou sangramento nos três períodos menstrual.
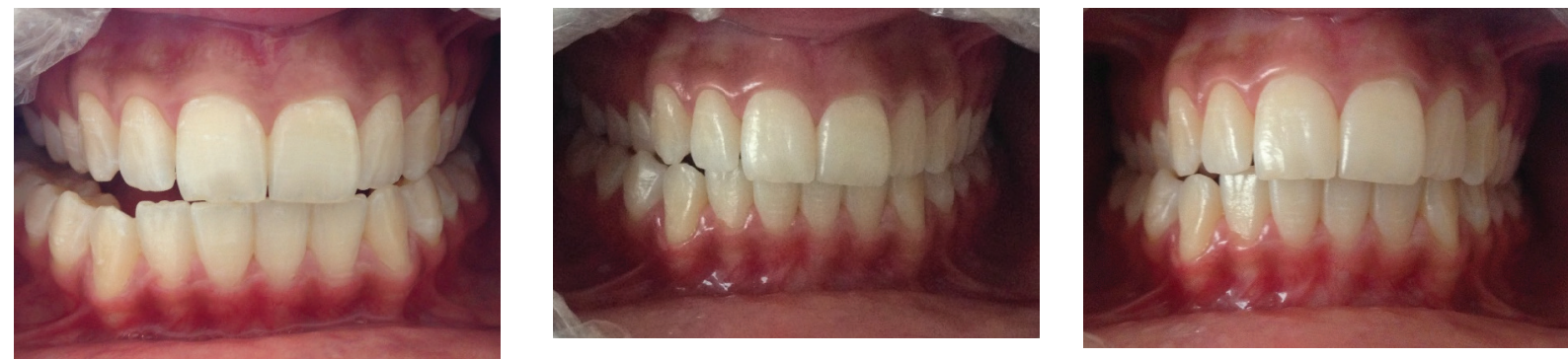

Figuras 28, 29 e 30: Imagens da voluntária 10, que apresentou sangramento nos períodos pré-menstrual e menstrual. 

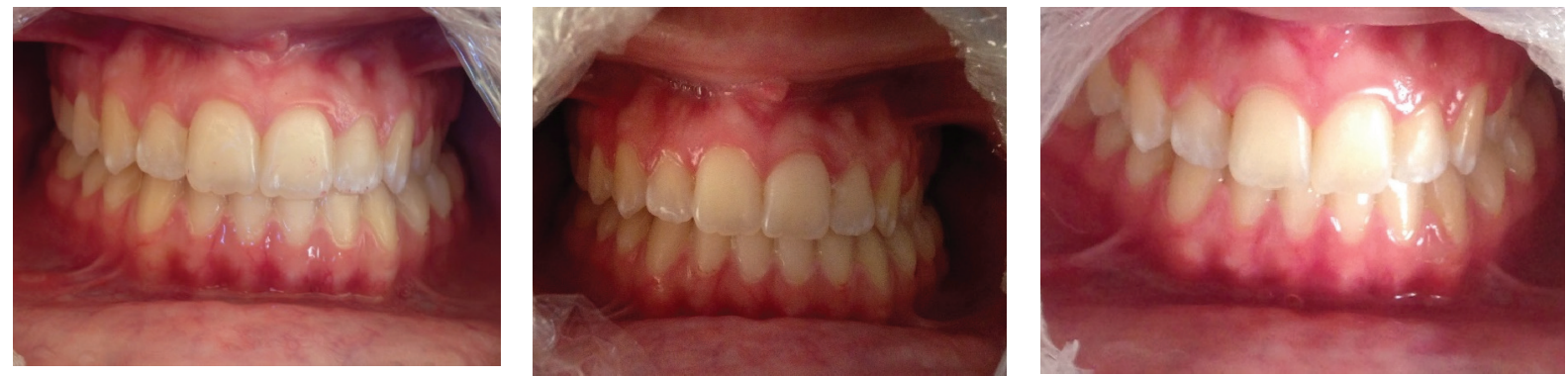

Figuras 31, 32 e 33: Imagens da voluntária 11, que apresentou sangramento nos períodos menstrual e pós-menstrual.
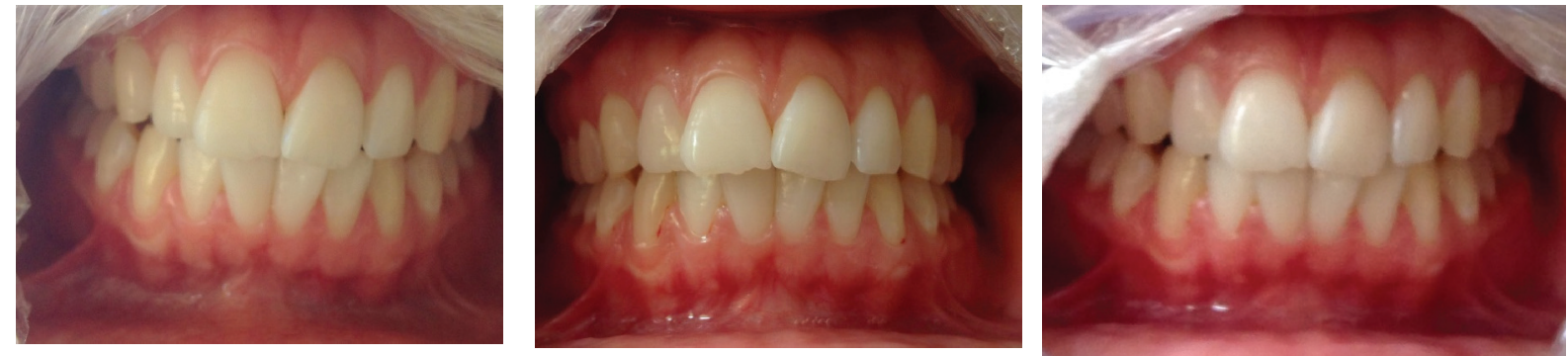

Figuras 34, 35 e 36: Imagens da voluntária 12, que apresentou sangramento no período menstrual.
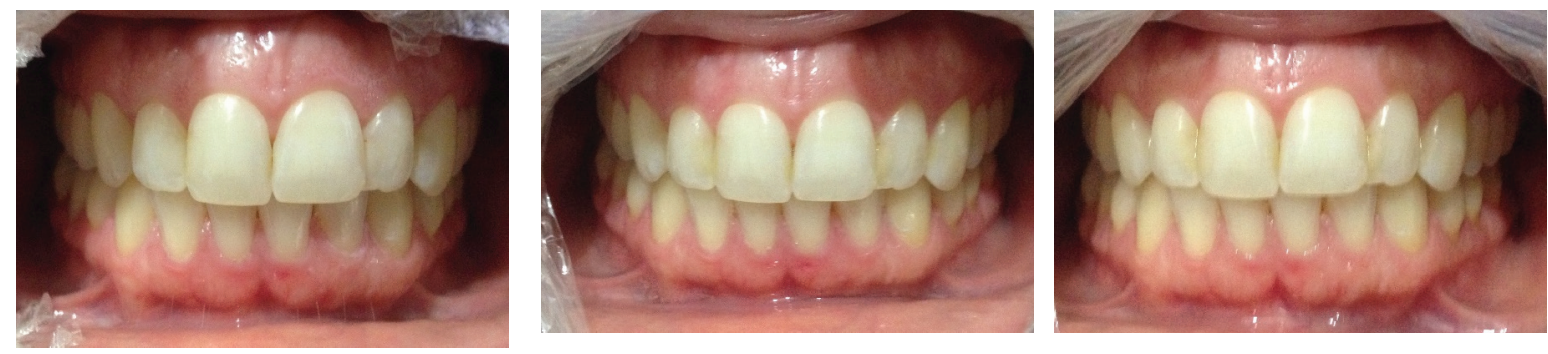

Figuras 37, 38 e 39: Imagens da voluntária 13, que apresentou sangramento no período menstrual.
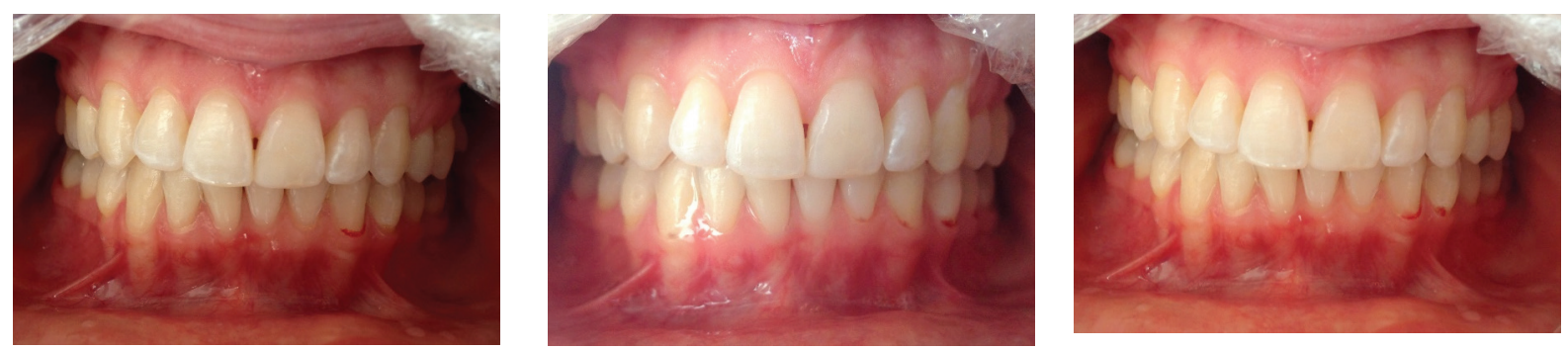

Figuras 40, 41 e 42: Imagens da voluntária 14, que apresentou sangramento nos três períodos menstrual.
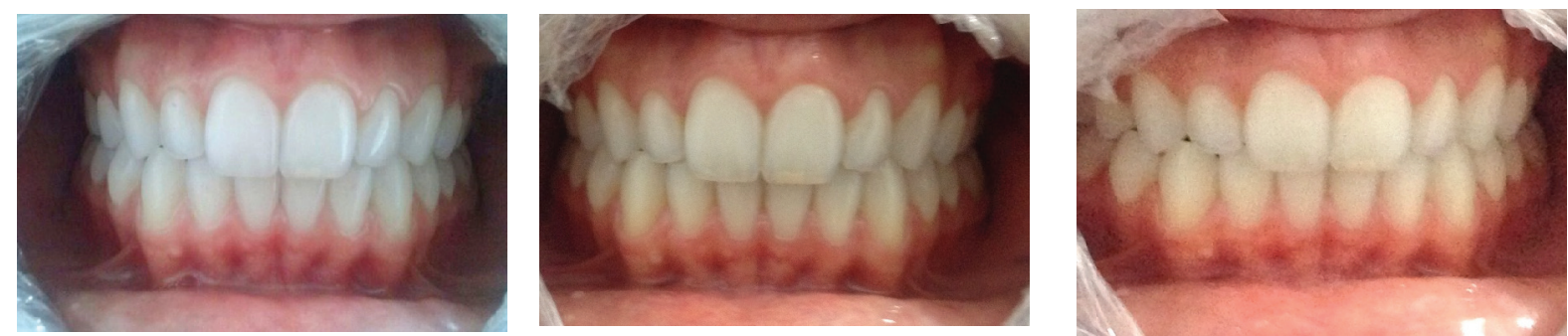

Figuras 43, 44 e 45: Imagens da voluntária 15, que não apresentou significativos sangramentos em nenhum dos períodos. 

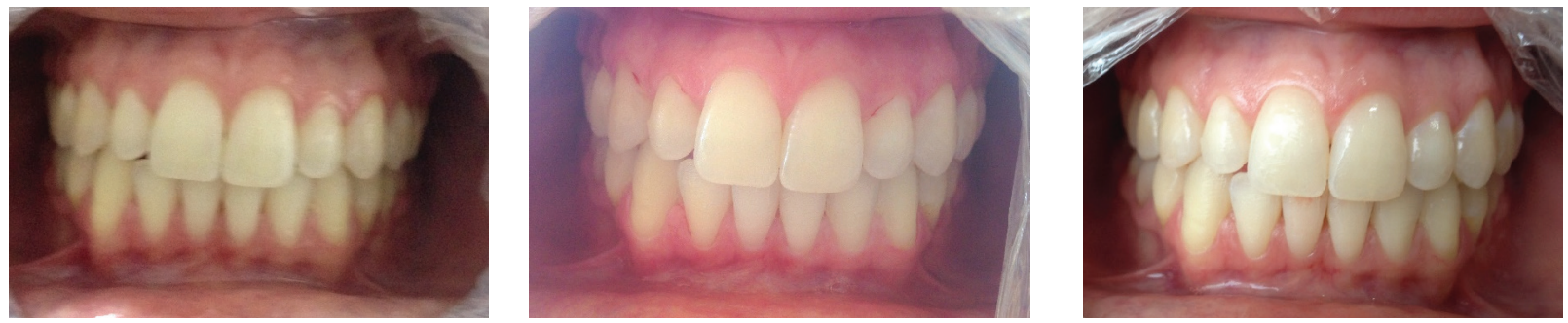

Figuras 46, 47 e 48: Imagens da voluntária 16, que apresentou sangramento no período menstrual.
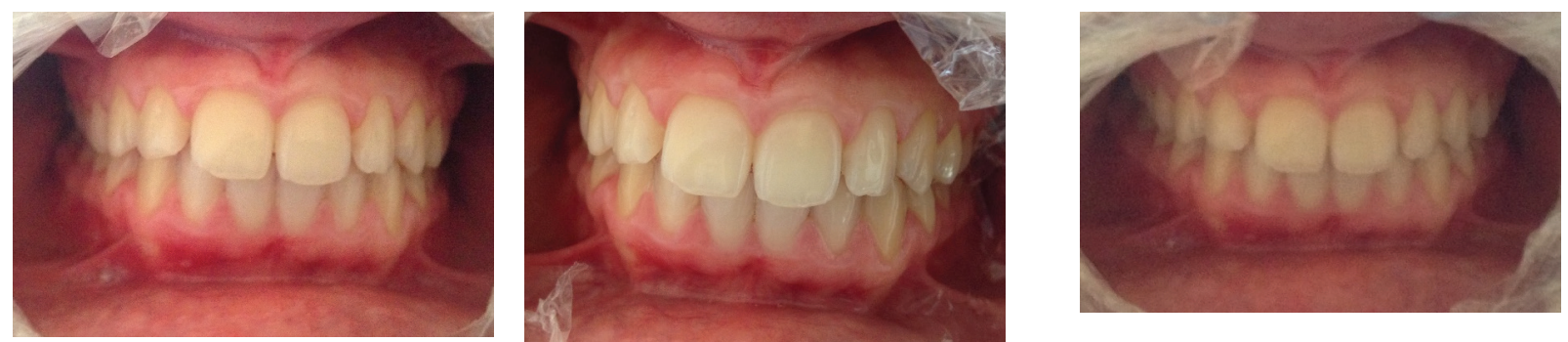

Figuras 49, 50 e 51: Imagens da voluntária 17, que apresentou sangramento nos três períodos menstrual.
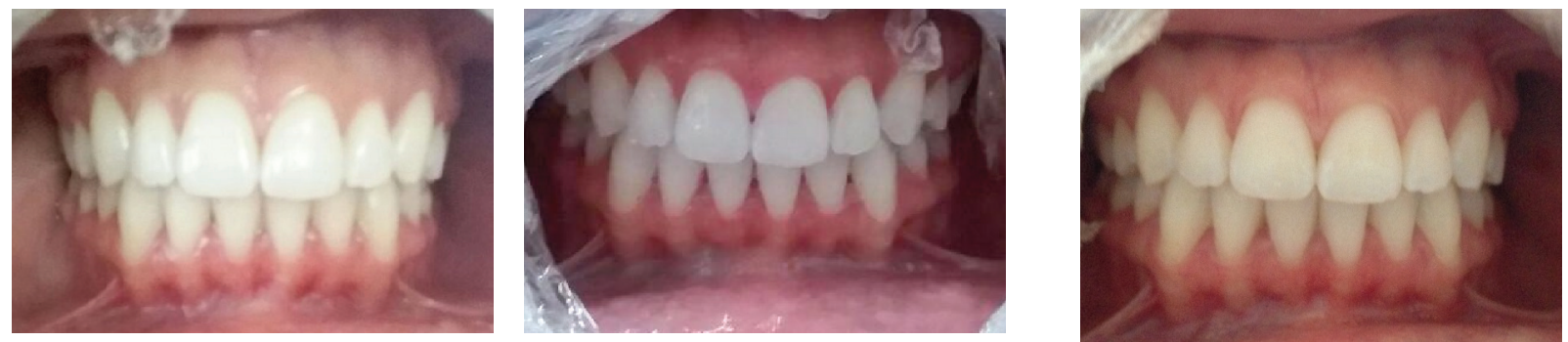

Figuras 52, 53 e 54: Imagens da voluntária 18, que não apresentou significativos sangramentos em nenhum dos períodos.
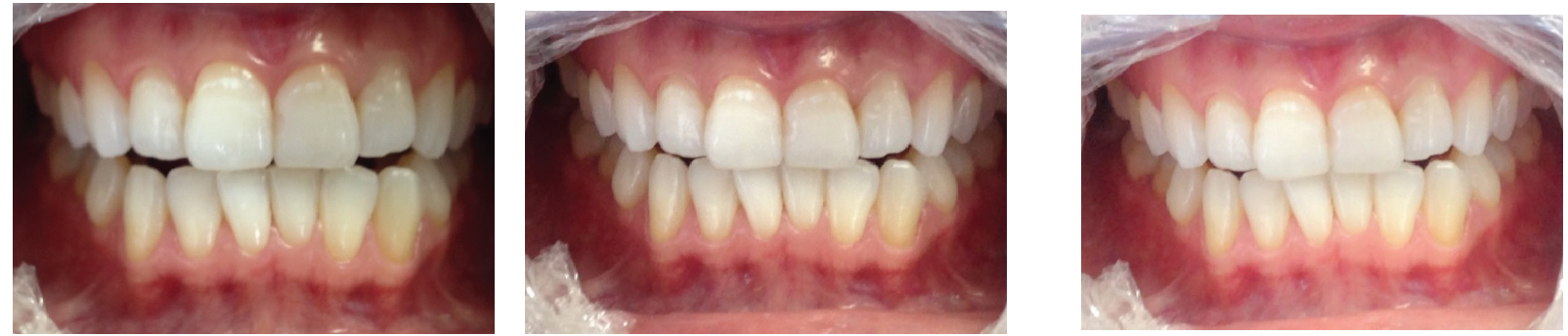

Figuras 55, 56 e 57: Imagens da voluntária 19, que apresentou sangramento no período menstrual.
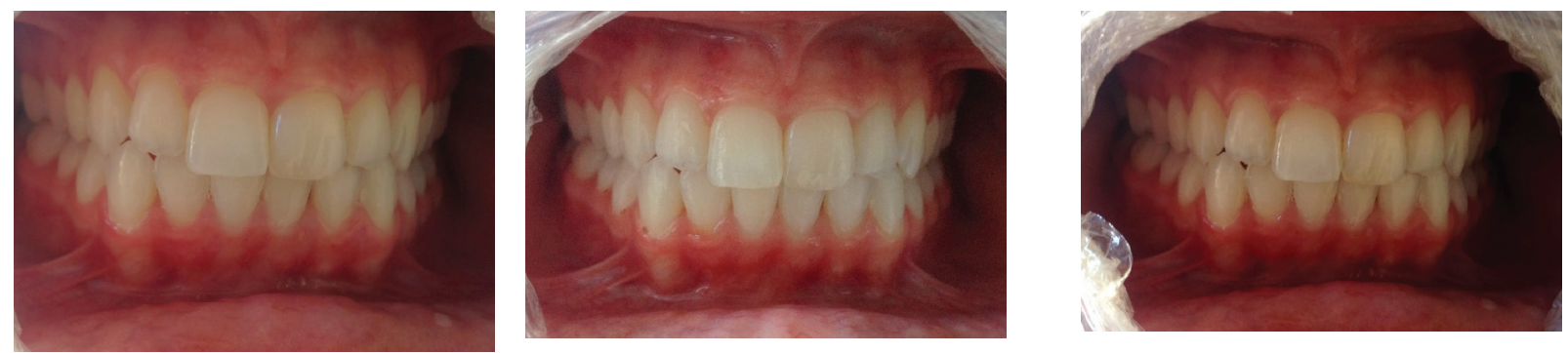

Figuras 58, 59 e 60: Imagens da voluntária 20, que apresentou sangramento no período menstrual. 


\section{RESULTADO DA AVALIAÇÃO CLÍNICA E SONDAGEM}

- $30 \%$ das voluntárias: sangramento antes do período menstrual

- 55\% das voluntárias: sangramento durante o período menstrual em mais de um dente

- $15 \%$ das voluntárias: sangramento após o período menstrual

- $60 \%$ das voluntárias: sentiram maior sensibilidade na sondagem durante o período menstrual

\section{CONSIDERAÇÕES FINAIS}

Após análise quantitativa dos resultados, concluiu-se que as alterações hormonais do período menstrual geram impacto direto nos tecidos gengivais, ou seja, contribuem para o aumento da a sensibilidade e o sangramento gengival.

\section{REFERÊNCIAS BIBLIOGRÁFICAS}

1. Oliveira LK, Oliveira LMB. A influência das alterações endócrinas e do estresse durante o ciclo menstrual sobre o periodonto. Rev. Ciências Médicas e Biológicas; Salvador. 2011 set/dez; v.10, n.3, p.284-289.

2. Zuza EP, Pires JR, Martins AT, Albarecci MFC, David MC, Toledo BEC. Avaliação da condição gengival em resposta aos picos hormonais do ciclo reprodutivo da mulher: estudo clínico controlado. Rev. Periodontia; 2010 set; v.20, n.03, p.60-66.

3. Santos JF, Pillon, FL. A influência dos hormônios sexuais femininos sobre a manifestação clínica das doenças periodontais - Revisão de literatura. Rev. Periodontia; 2009 set; v.19, n.03, p.34-40.

4. Glória VFV. Relação entre condições bucais e a saúde geral [Monografia]. Belo Horizonte: Universidade Federal de Minas Gerais - UFMG; 2011.

5. Alves C, Andion J, Brandão M, Menezes R. Mecanismos patogênicos da doença periodontal associada ao diabetes melito - Revisão de literatura. Rev. Arq Bras Endocrinal Metab; 2007 abril; v.7, p.51.

6. Offenbacher S, Beck JD, Jared HL, Mauriello SM, Mendoza LC, Couper DJ, Et al. Effects of periodontal therapy on rate of preterm delivery a randomized controlled trial. Obstret Gynecol; 2009 Semptember; v.03, n.114, p.551-559.

7. Bertolini PFR, Filho OB, Niero BG, Saraceni CHC, Splendore SMG, Pomílio A, Et al. Medicina periodontal e a mulher: a importância do seu conhecimento para uma abordagem preventiva por ginecologistas/obstetras e cirurgiões dentistas. Rev. Ciênc. Méd; Campinas; 2007 maio/jun; v.16, n.3, p.175-185.

8. Buencamino MCA, Palomo L, Thacker HL. How menopause affects oral health, and what we can do about it. Rev. Cleveland Clinic Journal of Medicine; 2009 october; v.76, n.8. 